\title{
Analysis Acoustical Formants Russian Fricative Consonants in Comparison with the Pronunciation of Iranian Students
}

\author{
Valipour Alireza ${ }^{1 *}$ \\ Professor of Russian Language and Literature, \\ Faculty of Foreign Languages and Literature, University of Tehran, \\ Tehran, Iran.

\section{Jamalzad Mohammad ${ }^{2}$} \\ $\mathrm{PhD}$ student of Russian Language and Literature, Faculty of Foreign Languages and \\ Literature, University of Tehran, \\ Tehran, Iran.
}

(date of receiving: December, 2020; date of acceptance: March, 2021)

\begin{abstract}
Knowledge of a foreign language, in addition to grammatical and lexical problems, is also associated with phonological problems, in all their aspects as acoustic and articulatory characteristics. Such problems should be solved in order to realize comprehensible communication as the main goal of teaching the Russian language with the maximum approximation of the original to the language. The experiment was aimed at improving the acoustic and pronunciation skills of Iranian students using the program "PRAAT". The purpose of the analysis is to identify the influence of the phonological and articulatory characteristic of the consonant system of the Persian language on the Russian language of Iranian students and eliminate this interfering influence on the studied language, as well as to correct and improve the pronunciation of students. The main research methods are the comparative-typological method, experimental methods and methods of measurement and differences, comparison and statistical processing of data. In the course of the experiment, differences were revealed in the articulation of a Russian native speaker and Iranian students.
\end{abstract}

Keywords: Acoustic, Fricative Consonants, Formant, Articulation.

1. Email: alreva@ut.ac.ir *Corresponding author

2. Email: mjamalzad1984@gmail.com 


\title{
Анализ акустических параметров русских щелевых согласных в сравнении с произношением иранских учащихся
}

\section{Валипур Алиреза ${ }^{1 *}$}

Профессор, Кафедра русского языка и литературы, Тегеранский университет, Тегеран, Иран.

\section{Джамалзад Мохаммад²}

Аспирант, Кафедра русского языка и литературы, Тегеранский университет, Тегеран, Иран.

(дата получения: декабрь 2020 г.; дата принятия: март 2021 г.)

\begin{abstract}
Аннотация
Владение иностранным языком кроме грамматических и лексических проблем также связано с фонологическими проблемами, во всех их аспектах как акустических, так и артикуляционных характеристик. Такие проблемы должны решаться, чтобы реализовать коммуникативность как основную цель обучения русскому языку при максимальном приближении оригинала к языку. Эксперимент был направлен на повышение акустических и произносительных навыков иранских студентов при помощи программы “Рraat". Целью анализа является выявление влияния фонологических и артикуляционных свойств консонантной системы персидского языка на русскую устную речь иранских студентов и устранение этого влияния на изучаемый язык, а также коррекция и улучшение произношения студентов. Основными методами исследования являются сопоставительно-типологический метод, экспериментальные методы и методы измерения сходства и различия, сравнения и статистической обработки данных. В ходе эксперимента были выявлены различия в артикуляции носителя русского языка и иранских учащихся.
\end{abstract}

Ключевые слова: Акустические Характеристики, Щелевые Согласные, Формант, Артикуляция.

1. Email: alreva@ut.ac.ir * Ответственный автор

2.Email:mjamalzad1984@gmail.com 


\section{Введение}

Акустика - это раздел фонетики, изучающий звуковые волны, создаваемые человеческими голосовыми органами для общения (Richards 1992. 274). Это касается передачи речевых звуков по воздуху. В 1952 г., наряду с прогрессом в области фонологии, Якобсон опубликовал «Предварительные сведения к анализу речи» - основополагающее произведение в форме небольшой книги, объединяющей акустическую фонетику и фонологическую теорию. После этой книги Фант создал акустическую теорию производства речи (Якобсон 1962. 173-230). С тех пор изучению фонетических единиц речи уделяется особое внимание.

Поскольку русский и персидский языки относятся к разным языковым группам (Бертельс 1932. 6-7), при усвоении русского языка иранскими студентами возникает много проблем. Такие проблемы охватывают не только грамматические и лексические аспекты в обоих языках, но и фонетическую систему во всех их аспектах как акустические, так и артикуляционные характеристики. Учитывая сложность русского языка (Zahraie 2018) и такое несовпадение в неродной среде приводит ко многим трудностям в образовании учащихся особенно на начальных этапах.

Артикуляционные и акустические характеристики русских звуков рассматриваются в работах многих ученых: Л.Р. Зиндер (1979), М.И. Матусевич (1976), Логинова (2017) и другие. К сожалению, то, что относится к иранской части по сравнению с русской, достижений не так много. Работу, проделанную в этой области, можно увидеть в трудах таких лингвистов, как Хагшенаш (Haghshenas 2015), Бидженхан (Bijankhan 2013) и Модаресси (Modaressi 2019). Основным препятствием является недостаточная изученность проблемы интерференции и классификации ошибок произношения студентов (Ткач 2010. 22). В настоящее время не существует экспериментального исследования, в котором анализируется проблема 
произношения иранских учащихся. Такой подход помогает нам понять потенциальную интерференцию в области фонетики и произношения русских щелевых согласных и выявить причины их появления (Черепко 2020. 307).

\section{Основная часть}

C помощью спектрограммы формант F1 и F2 был измерен в произнесении носителя русского языка и иранских учащихся.

В эксперименте участвовали 8 мужчин: 4 носителя русского языка и 4 иранских студента. Средний возраст участников в эксперименте, составил 25 лет. Голоса русских носителей были записаны в России и голоса иранских учащихся в Иране. Звуки были записаны с частотой 44100 Гц в лаборатории.

Изучение аудиофайлов в этом исследовании проводилось с помощью программы Praat (6.1.35). Praat предназначен для анализа и реконструкции акустических речевых сигналов как объективной оценки произношения и одновременно как наглядного иллюстративного материала (Weenink 2018; Musavi 2015. 17-30). Программа преобразует звуковые сигналы в видимые спектры: осциллограммы и спектрографы, которые представлены в настоящем разделе (Johnson 2015. 80-82).

В речевых сигналах горизонтальная ось показывает время и вертикальная ось - амплитуду (Hayward 2000. 54; Valipour 2014. 21).

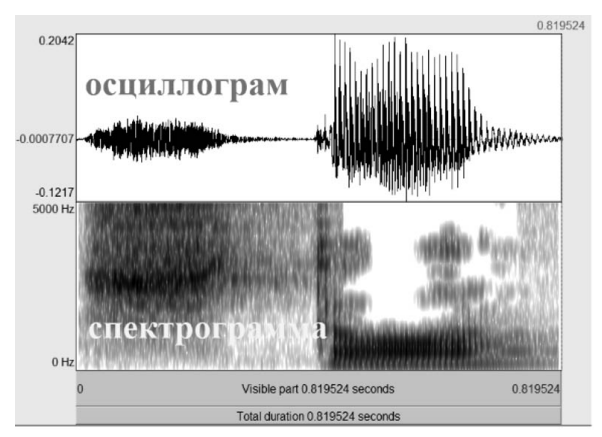

Рис. 1. Слово «что» в программе Praat. 


\section{1. Форманты F1 и F2}

Формант в фонетике определяется как широкий пик или максимум в спектре, возникающий в результате акустического резонанса голосового тракта человека. Формант F1 показывает смычность согласных звуков. Если формант F1 невелико, то образуется смычный согласный. Формант F2 определяет место образования преграды. Невеликое количество форманта F2 означает, что мы имеем дело с губной артикуляцией, великое количество этого показателя свидетельствует о палатализации согласного и ее средне-высокий формант F2 показывает переднеязычную артикуляцию. У губных все форманты имеют низкие значения. (Князев 2011. 105-110).

\section{Полученные информации F1 в виде диаграммы.}
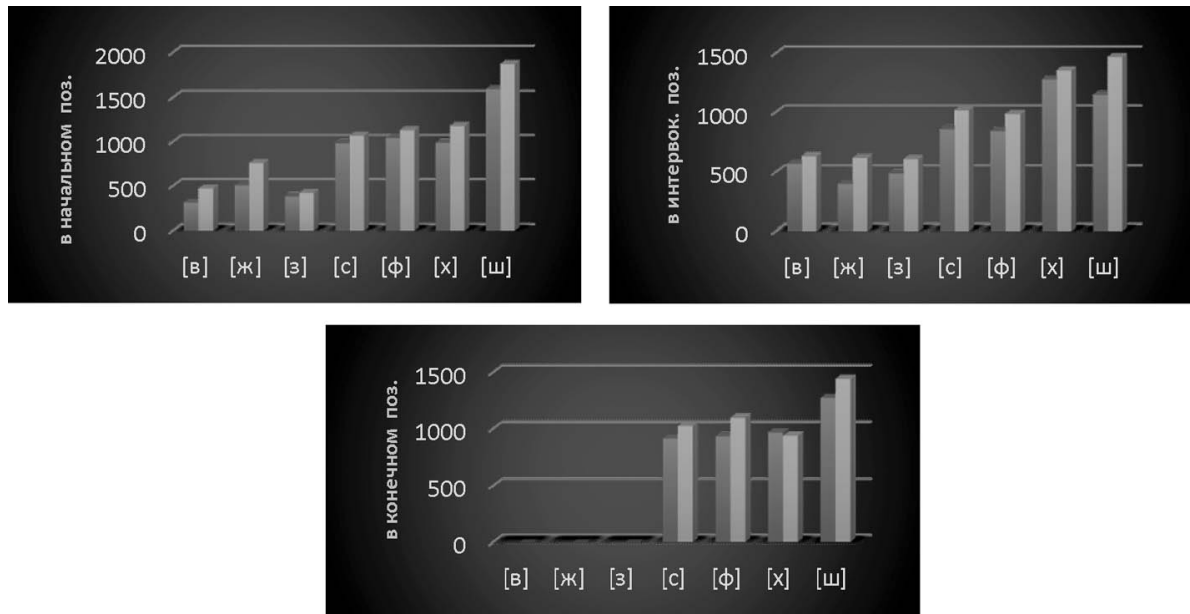

Графика 1. Формант F1 твёрдых щелевых звуков у носителя русского языка (синий) и иранских учащихся (красный). 

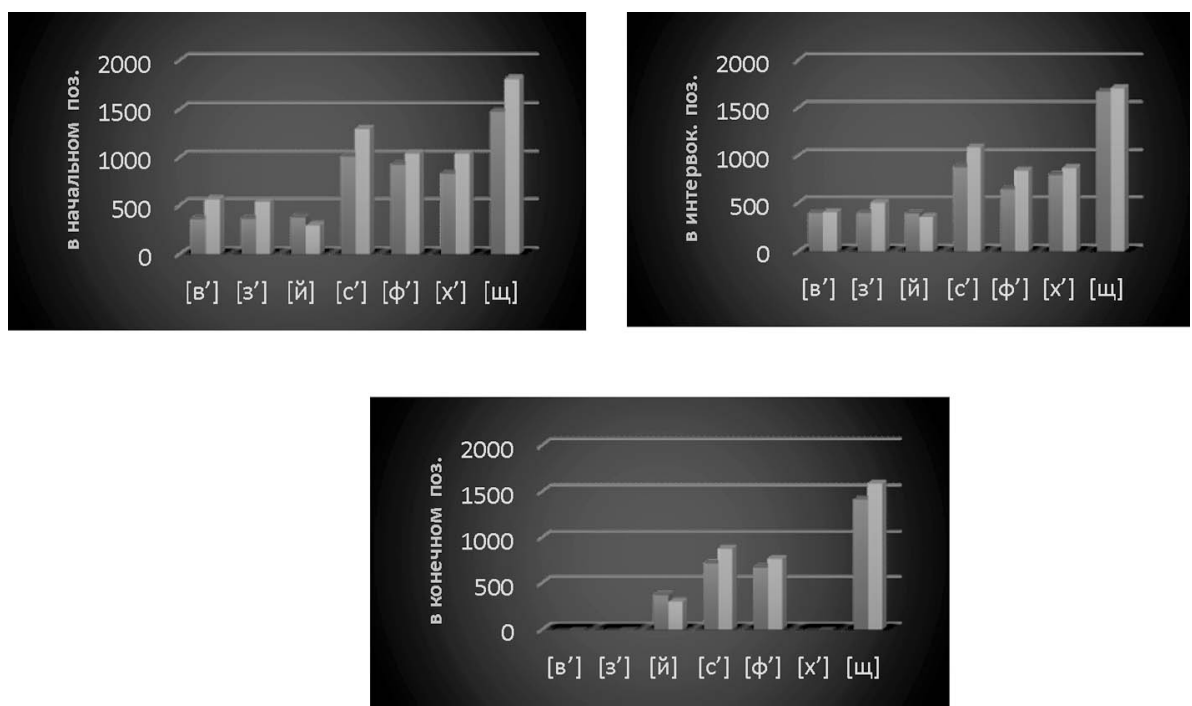

Графика 2. формант F1 мягких щелевых звуков у носителя русского языка (синий) и иранских учащихся (красный).

Рассмотрение форманты F1 показывает, этот показатель для остальных звуков в произнесении иранских учащихся выше, чем у носителей (кроме звука [й]). Поскольку этот показатель связан с смычностью, можно сказать губы при произношении звуков [в], [ж], [3], [c], [ф], [х], [ш], [в'], [3’], [c'], [ф’], [х’] и [щ], у носителей более открыты, чем у иранцев. Конечно, это различие не большое.

Как пишет Любимова в своей книге (Любимова 2019), губы во время произношения всех русских щелевых согласных у носителя, слегка приоткрыты. Но Самарэ при описании аналогичных звуков в персидском языке не упоминает об открытости губ (Samare 2018).

Артикуляции звуков [c], [c’'], [3] и [3’] ещё показывает другую разницу. При произношении твёрдые звуки [s] и [z] (которые иранские студенты произносят вместо звуков [c], [c'], [3] и [3’]) в персидском языке кончик языка приближается к верхним альвеолам зубов и располагается очень близко к 
нему, но в русском языке при произношении звук [c], [c'], [3] и [3’] кончик языка упирается в основание нижних зубов. Такая форма языка образует более округлую щель в сравнение со звуком $[\mathrm{s}]$ и $[\mathrm{z}]$ в персидском языке. Это подтверждают и результаты наших наблюдений.

Звук [й] наоборот. У иранских учащихся воздух свободно проходит по центру ротовой полости. В целом артикуляционное сужение больше, чем у гласных, а это понижает F1.

В русском языке звук [й] является среднеязычным щелевым сонантом. При его образовании язык продвинут вперед, имеет круглую форму и средняя часть спинки языка высоко поднята к твердому нёбу. Передняя и задняя части языка круто опущены. На пути воздушной струи образуется преграда в результате сближения средней и незначительно передней части спинки с участком твердого нёба. Края передней части языка упираются в боковые нижние зубы. Кончик языка лежит у основания нижних резцов. Мягкое нёбо поднято. Голосовые связки сближены, напряжены и колеблются. Губы слегка растянуты в уголках (Любимова 2019. 180).

Полученные данные подтверждают, что иранские учащиеся вместо звука [й] в русском языке произносят персидский согласный [j]. В персидском языке при произношении этого гласного звука передняя часть языка поднимается к твердому небу, и расположена на расстоянии, от которого воздух может проходить без трения. Кончик языка свободен и стоит за нижними зубами. Средняя часть края языка прижимается к стенам верхних зубов. Расстояние между верхними и нижними зубами 2-3 миллиметра. Мягкое небо поднято и закрывает проход воздушной струи через нос. Губы растянуты и левые и правые углы губ слегка растянуты (Samare 2018).

Этот звук по артикуляции очень близок гласному звуку [i]. При произношении гласных смычность меньше, чем согласных. Этот факт подтверждается статистикой в таблице и F1 в произнесении иранских 
учащихся по крайней мере 15 \% меньше, чем у носителей. Кроме того, губы более растянуты по сравнению с произношением носителя русского языка.

\section{Полученные данные F2 в виде диаграммы}
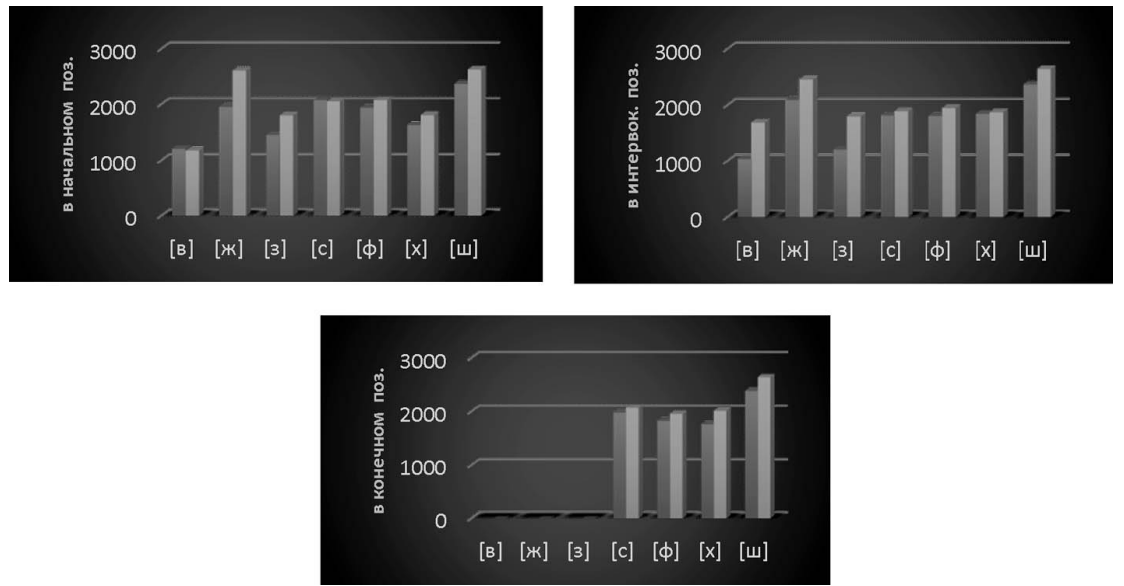

Графика 3. Формант F2 твёрдых щелевых звуков в конечной позиции у носителя русского языка и иранских учащихся.
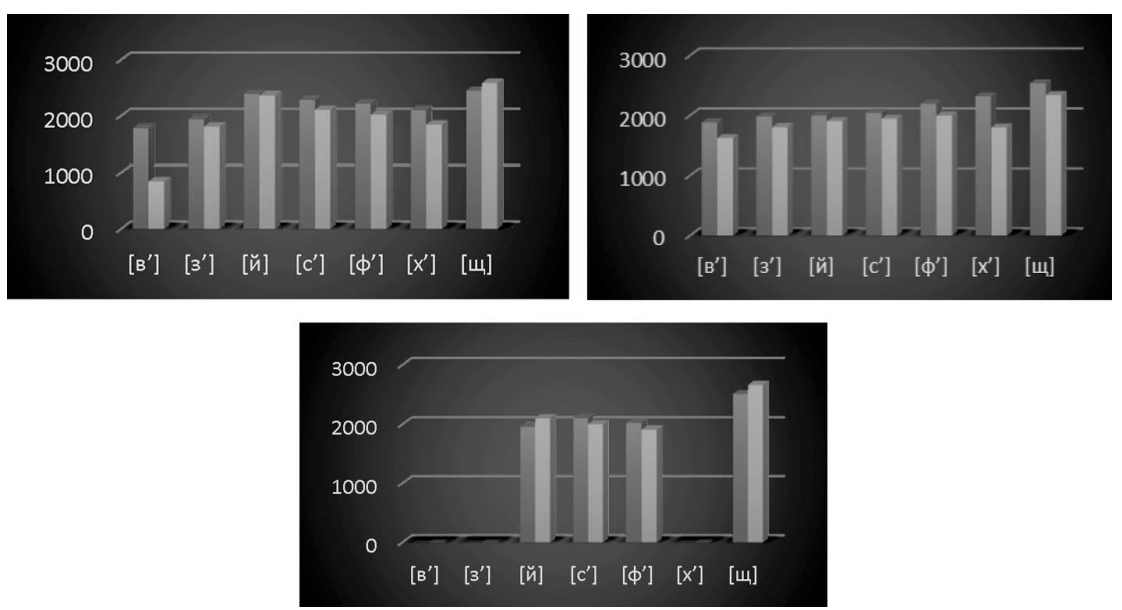

Графика 4. Формант F2 мягких щелевых звуков у носителя русского языка (синий) и иранских учащихся (красный). 
Результаты показывают, что форманты F2 у русских мягких согласных

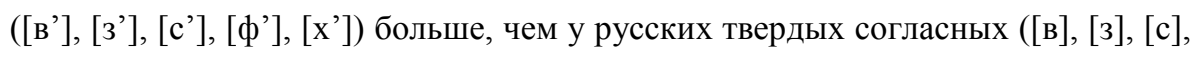
$[ф],[x])$ в произнесении носителей языка. В среднем этот показатель больше на 25 \%. Это свидетельствует о палатальности мягких русских согласных по сравнению с твёрдыми.

Показатели мягких согласных [в'], [3’], [c'], [ф'], [х'] в произнесении носителей русского языка заметно выше, чем в произнесении иранских учащихся. Это доказывает, что иранские учащиеся при произношении не соблюдают поднятие средней части спинки языка к твёрдому нёбу. Спинка языка при произнесении этих звуков у носителя русского языка очевидно поднимается к твердому нёбу.

В отличие от вышеупомянутых звуков, F2 для звука [ж] и [ш] наоборот в произнесении иранских учащихся значительно больше, чем у носителей русского языка.

В русском языке в момент образования звук [ш] передняя часть языка, включая кончик, приподнята вверх, к альвеолам. При этом средняя часть спинки языка выгнута, а задняя, наоборот, приподнята в сторону мягкого нёба. Воздух проходит, таким образом, через две щели: сначала через щель, образуемую задней частью спинки языка (первый фокус образования шума) или на границе средней и задней части, а затем через щель, образуемую приподнятым кончиком и передней частью языка (второй фокус образования характерного шума). Поэтому этот звук всегда произносится твёрдым (Любимова 2019. 107-110).

Изучение произношения иранских учащихся показало, что они используют персидский согласный [š] вместо звука [ш]. В персидском языке переднеязычный звук [š] как в русском является двухфокусным. В первом фокусе при помощи языка и верхних альвеол образуется узкая щель для прохода воздуха. Кончик языка поднимается и стоит перед задним частью 
альвеол. Край языка прижимается к стенкам верхних зубов. Мягкое небо поднято и закрывает проход воздушной струи через нос. Расстояние между нижними и верхними зубами небольшое. Во втором фокусе средняя часть спинки языка в отличие от [ш] поднимается к нёбу. Поэтому этот звук всегда произносится мягким (Samare 2018. 67-70).

В русском языке положение языка в момент артикуляции [ж] в принципе такое же, как и при [ш], только язык менее напряжен. При образовании [ж] имеется два фокуса: передний - в месте сближения кончика языка с верхними зубами и задний - в месте сближения задней части спинки языка с мягким нёбом или границей твердого и мягкого нёба. Свистящие щелевые согласные противопоставлены шипящим щелевым в русском языке как дорсальные какуминальным. Спинка языка при [ж] обязательно прогибается в средней части (приподняты передняя часть языка вместе с кончиком и задняя часть спинки языка) (Любимова 2019. 78-85).

Изучение произношения иранских учащихся показало, что они используют персидский согласный [ž] вместо звука [ж]. Этот звук произносится как [ธ̌]. Он тоже двухфокусный. Этот звук всегда произносится мягким потому, что во втором фокусе средняя часть спинки языка поднимается к нёбу. Поэтому этот звук в отличие от русского согласного звука [ж] всегда произносится мягким (Samare 2018. 67-70).

\section{Заключение}

Результаты исследования показывают, что ошибки в реализации согласных непосредственно зависят от особенностей консонантных систем русского и персидского языков и однотипных артикуляций при образовании сравниваемых согласных не существует. В произнесении щелевых согласных носителей русского языка и иранских учащихся существует большая и принципиальная разница. Именно из-за таких различий появляется акцент. 
Различие между формантами F1 и F2 показывает, что артикуляция у иранских студентов соответствует системе своего родного языка, а не системе русского языка.

Губы во время произношения всех русских щелевых согласных у носителя русского языка более открыты, чем у иранских студентов.

Произношение звук [ж] в русском языке и [ž] в персидском языке заметно отличается. В русском языке при произношении [ж] спинка языка обязательно прогибается в средней части. Передняя часть языка вместе с кончиком и задняя часть спинки языка приподняты. Этот звук в русском языке считается твёрдым. Но в персидском языке в отличие, средняя часть спинки языка поднимается к нёбу. Поэтому этот звук всегда произносится мягким в персидском языке.

Персидский звук [ธّ̌] соответствует звуку [щ] в русском языке. Анализ артикуляции звука показывает, что как [щ] в русском, здесь также во втором фокусе средняя часть спинки языка поднимается к нёбу. В отличие от звука [ш], для образования которого задняя часть спинки языка приподняты, а не средняя. Иранские учащиеся используют этот звук одновременно вместо звука [ш] и [щ].

Иранские учащиеся произносят звук [j] взамен [й] в русском языке. Этот звук самый близкий к звуку [й] в фонетической системе персидского языка. Во время образования звук [j], расстояние между языком и твёрдым небом, вызывает воздух проходить без трения. Но при произношении [й] на пути воздушной струи образуется преграда в результате сближения средней и незначительно передней части спинки с участком твердого нёба. Это создаёт большое различие с оригинальным произношением. 


\section{Литература}

1- Бертельс, Е.Э. (1932). Учебник персидского языка. Ленинград: Издание Ленинградского Восточного Института.

2- Валипур, А., \& Джамалзад М. (2020). Экспериментальное исследование особенностей произнотения русских щелевых согласных при обучении иранских студентов. Вестник Пермского национального исследовательского политехнического университета. Проблемы языкознания и педагогики, (2). $188-201$.

3- Зиндер, Л. Р. (1979). Общая фонетика: учебное пособие. М.: Высшая школа.

4- Князев, С. В., Пожарицкая С. К. (2011). Современный русский литературный язык. Москва: Гаудеамус. $432 \mathrm{c.}$

5- Логинова, И. М. (2017). Очерки по методике обучения русскому произночению: учебное пособие. Москва: РУДН.

6- Любимова, Н. А. (2019). Лингвистические основы обучения артикуляции русских звуков. 2-е изд., стереотип. М.: русский язык.

7- Матусевич, М.И. (1976). Современный русский язык. Фонетика. М.: Просвещение.

8- Ткач, Т. Г. (2010). Лингводидактические основы обучения русской фонетике будущих филологов-русистов в высшей школе Ирана. российский университет дружбы народов. Москва.

9- Черепко, В. В., \& Ахнина, К. В. (2020). Особенности произношения русских переднеязычных щелевых и аффрикат японскими студентами. Теория языка и межкультурная коммуникация, (2), 307-318.

10- Якобсон, Р., \& Фант, Г. М., \& Халле, М. (1962). Введение в анализ речи. Новое в лингвистике, 2, 204.

11- Bijankhan, M. (2013). Phonetic system of the Persian language. Tehran: SAMT. [In Persian]

12- Haghshenas, Ali Mohammad. (2014). Phonology. Persian edition (Faros Iran). Tehran: Agah. [In Persian]

13- Hayward, K. (2000). Experimental phonetics. Harlow: Pearson Education Limited. [In English].

14- Johnson, K. (2015). Acoustic and auditory phonetics. Translated by Zahra Mahmoudzadeh. Iranian Research Institute for Information Science and Technology. Tehran. Chapar. [In Persian]

15- Modarresi Ghavami, Golnaz (2019). Phonetics: The Scientific Study of Speech. Tehran: SAMT. [In Persian] 
16- Mousavi, Neda (2015). PRAAT Doing Phonetics by Computer. Tehran: Neviseh Parsi. [In Persian]

17- Richards, J. C., \& Tung, P., \& Ng, P. (1992). The culture of the English Language teacher: A Hong Kong example. RELC journal, 23(1), 81-102. [In English].

18- Samareh, Yadollah \& Nilipour, Reza. (2018). Persian phonology. Sounds and making phonetic syllables, Tehran: Markaze nashr-e daneshgahi. [In Persian]

19- Valipour, Alireza. (2014). Russian phonetic. Tehran: SAMT. [In Persian]

20- Weenink, D. (2018). Speech signal processing with Praat. University of Amsterdam. [In English].

21- Zahraei, Seyed Hassan (2018). Russian language instruction. Tehran: SAMT. [In Persian]

\section{Bibliography}

1- Bertel's, E. Je. (1932). Uchebnik persidskogo jazyka. Leningrad: Izdanie Leningradskogo Vostochnogo Instituta.

2- Valipur, A., \& Dzhamalzad M. (2020). Jeksperimental'noe issledovanie osobennostej proiznoshenija russkih shhelevyh soglasnyh pri obuchenii iranskih studentov. Vestnik Permskogo nacional'nogo issledovatel'skogo politehnicheskogo universiteta. Problemy jazykoznanija i pedagogiki, (2). 188-201.

3- Zinder, L. R. (1979). Obshhaja fonetika: uchebnoe posobie. M.: Vysshaja shkola.

4- Knjazev, S. V., Pozharickaja S. K. (2011). Sovremennyj russkij literaturnyj jazyk. Moskva: Gaudeamus. 432 s.

5- Loginova, I. M. (2017). Ocherki po metodike obuchenija russkomu proiznosheniju: uchebnoe posobie. Moskva: RUDN.

6- Ljubimova, N. A. (2019). Lingvisticheskie osnovy obuchenija artikuljacii russkih zvukov. 2-e izd., stereotip. M.: russkij jazyk.

7- Matusevich, M. I. (1976). Sovremennyj russkij jazyk. Fonetika. M.: Prosveshhenie.

8- Tkach, T. G. (2010). Lingvodidakticheskie osnovy obuchenija russkoj fonetike udushhih filologov-rusistov $v$ vysshej shkole Irana. rossijskij universitet druzhby narodov. Moskva.

9- Cherepko, V.V., \& Ahnina, K.V. (2020). Osobennosti proiznoshenija russkih perednejazychnyh shhelevyh $i$ affrikat japonskimi studentami. Teorija jazyka i mezhkul'turnaja kommunikacija, (2), 307-318.

10- Jakobson, R., \& Fant, G.M., \& Halle, M. (1962). Vvedenie v analiz rechi. Novoe v lingvistike, 2, 204. 
11- Bijankhan, M. (2013). Phonetic system of the Persian language. Tehran: SAMT. [In Persian]

12- Haghshenas, Ali Mohammad. (2014). Phonology. Persian edition (Faros Iran). Tehran: Agah. [In Persian]

13- Hayward, K. (2000). Experimental phonetics. Harlow: Pearson Education Limited. [In English].

14- Johnson, K. (2015). Acoustic and auditory phonetics. Translated by Zahra Mahmoudzadeh. Iranian Research Institute for Information Science and Technology. Tehran. Chapar. [In Persian]

15- Modarresi Ghavami, Golnaz (2019). Phonetics: The Scientific Study of Speech. Tehran: SAMT. [In Persian]

16- Mousavi, Neda (2015). PRAAT Doing Phonetics by Computer. Tehran: Neviseh Parsi. [In Persian]

17- Richards, J. C., \& Tung, P., \& Ng, P. (1992). The culture of the English Language teacher: A Hong Kong example. RELC journal, 23(1), 81-102. [In English].

18- Samareh, Yadollah \& Nilipour, Reza. (2018). Persian phonology. Sounds and making phonetic syllables, Tehran: Markaze nashr-e daneshgahi. [In Persian]

19- Valipour, Alireza. (2014). Russian phonetic. Tehran: SAMT. [In Persian]

20- Weenink, D. (2018). Speech signal processing with Praat. University of Amsterdam. [In English].

21- Zahraei, Seyed Hassan (2018). Russian language instruction. Tehran: SAMT. [In Persian]

\section{HOW TO CITE THIS ARTICLE}

Valipour, A., Jamalzad, M. (2021). Analysis Acoustical Formants

Russian Fricative Consonants in Comparison with the

Pronunciation of Iranian Students. Issledovatel'skiy Zhurnal Russkogo Yazyka I Literatury, 9(2), 11-25.

DOI: $10.52547 /$ iarll.18.11

URL: https://www.journaliarll.ir/index.php/iarll/article/view/199 


\title{
تجزيه و تحليل ويزگى هاى آكوستيكى همخوانهاى سايشى زبان روسى در
}

\section{مقايسه با تلفظ دانشجويان ايرانى}

\author{
عليرضا ولى يور \\ استاد گروه زبان و ادبيات روسى، دانشگاه تهران،

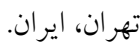 \\ محمد جمالزاد \\ دانشجوى دكترى آموزش زبان روسى گروه زبان و ادبيات روسى، دانشگاه تهران،

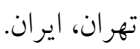 \\ (تاريخ دريافت: دسامبر ·r·r: تاريخ يذيرش: مارس (Y.Y)
}

تسلط بر يكى زبان خارجى علاوه بر مشكلات دستورى و لغـوى، بـا مسشكاتلات آوايسى در

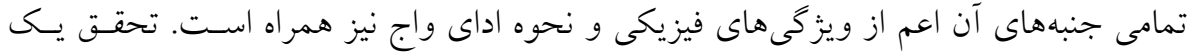

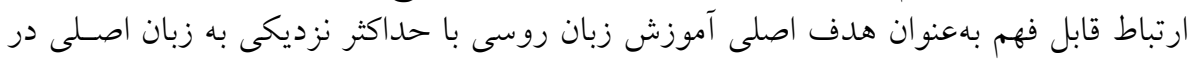

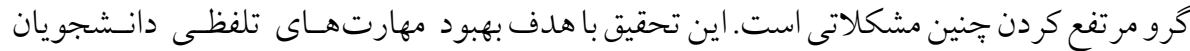

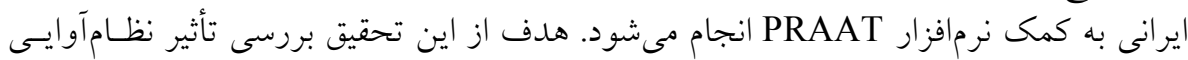
هم خوانهاى سايشى زبان فارسى بر كفتار شفاهى روسى دانشجويان ايرانى و امكان رفــع ايسن

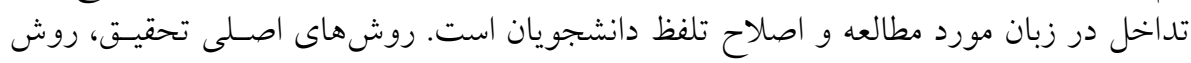

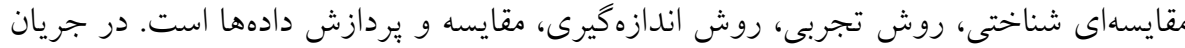

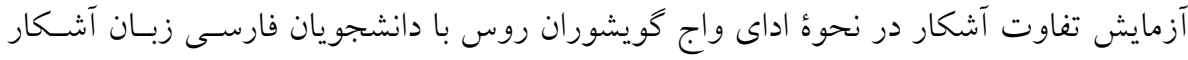

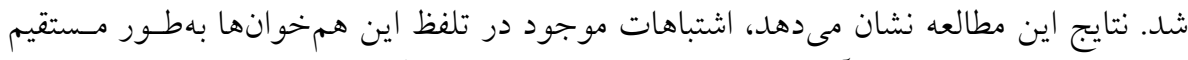

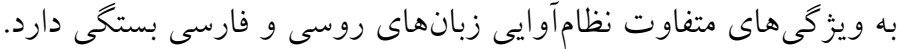

وازگَان كليدى: همخوانهاى سايشى، ويزگگ هاى فيزيكى صوت، سازه، نحوه اداى واج.

1. Email: alreva@ut.ac.ir *ويسنده مسئول

2. Email: mjamalzad1984@gmail.com نوع مقاله: علمى - يُزوهشى منئول 